\title{
INFRAESTRUTURAS RODOVIÁRIAS E MORFOLOGIA URBANA Parâmetros e relações em diálogo com o urbanismo moderno
}

\author{
ROAD INFRASTRUCTURES AND URBAN MORPHOLOGY \\ Parameters and relations in dialogue with modern urbanism
}

\author{
A. Pedro B. de Moraes \\ Universidade Federal do Rio de Janeiro, Brasil \\ pedrobarretodemoraes@gmail.com
}

\begin{abstract}
RESUMO
O artigo aqui apresentado parte da importância que infraestruturas rodoviárias possuem sobre a formação das metrópoles brasileiras, para propor uma leitura de suas características espaciais e possibilitar reflexões que contribuam com a evolução do território. Para tal, se utiliza de reflexões sobre as lógicas conformadoras do espaço, recorrendo, posteriormente, a projetos e conceitos do urbanismo moderno, com a intenção de resgatar ideias aptas a contribuir para uma sintaxe mais adequada à complexidade das relações emergentes entre eixos viários e a paisagem urbana.
\end{abstract}

Palavras-chave: urbanismo. infraestrutura. metrópole.

Linha de Investigação: 1: Cidade e projeto

Tópico: morfologia urbana

\section{ABSTRACT}

This article starts from the importance of road infrastructures on the formation of Brazilian metropolises, in order to propose a reading of their spatial characteristics and contribute to the reflections on the evolution of the territory. For such, it resorts on the logics that shape the space, attempting, later, to projects and concepts of the modern urbanism, aiming to rescue ideas that contribute to a more adequate syntax, concerning the complexity of the emerging relationships between road axes and the urban landscape.

Keywords: urbanism. infrastructure. metropolis.

Research Line: 1: City and project

Topic: urban morphology 


\section{XII $\quad$ SÃOPAULO $15 \sim 17 \cdot$ LISBOA $25 \sim 26$ JUN 2020}

\section{Introdução}

As principais metrópoles brasileiras têm, na infraestutura rodoviária, um elemento condicionante comum, que funciona como base para a urbanização, para a acumulação de capitais e a diferenciação do espaço necessária à comercialização da terra (KLEIMAN, 1994, p. 46-47). O uso do automóvel como principal meio de locomoção pela população se liga diretamente ao que Flávio Villaça (2001, p. 329) define como uma "luta de classes pelo domínio das condições de deslocamento espacial", constituída como a principal "força determinante da estruturação do espaço intraurbano brasileiro".

Dados os altos preços do solo em regiões centrais e a baixa qualidade dos sistemas de transporte público, eixos viários minimamente estruturados costumam atrair intensa ocupação urbana, somada a grandes volumes de tráfego. Assim, vias implementadas inicialmente em áreas periféricas, voltadas a conexões regionais, implantações industriais ou amplos enclaves, são incorporadas pelo crescimento urbano, absorvendo, em primeiro lugar, um excedente populacional que não pode arcar com localizações centrais e, em segundo lugar, sistemas de transporte, que surgem como "subproduto do sistema interurbano" (VILLAÇA, 2001, p. 82).

A partir deste processo, estradas, rodovias ou vias expressas acabam por incorporar funções, dinâmicas ou ocupações características de vias locais, configurando-se como tipologias rodoviárias híbridas, ou o que Álvaro Domingues (2010) denomina como "ruas da estrada", metaforicamente descritas como cordas "onde tudo se pendura". Marcados por escalas e fluxos discrepantes, definidos pelo contraste entre uma ordem vertical, hierárquica e racional, e uma ordem horizontal, localmente tecida (SANTOS, 2002), os espaços delimitados por estas infraestruturas resultam dificilmente legíveis, frequentemente identificados ao caos, à desordem ou ao erro.

Pier Vittorio Aureli (2014, p. xiv) afirma que, da incapacidade do campo da arquitetura para produzir uma teoria capaz de lidar com tal complexidade, surge uma "enciclopédia hipertrofiada" de caráter interdisciplinar que, no entanto, não dá conta de apreender e descrever as dinâmicas e relações que configuram estes espaços, inicialmente periféricos e posteriormente consolidados, e distantes de um vocabulário tradicional, seja em termos técnicos ou formais.

Cabe, portanto, o questionamento colocado por Alex Wall (2014, p. 218): se as rodovias são um instrumento tão eficaz na urbanização da cidade-região, quais são suas qualidades urbanas? Bernardo Secchi $(2014, p$. 207) propõe uma aproximação ao tema que, em lugar de repudiar a cidade moderna, busque dialogar com suas "ordens morfológicas, princípios de assentamento e suas relações mútuas", superando visões setoriais, buscando novas sintaxes e entendimentos dinâmicos.

Este artigo realiza uma leitura sobre urbanizações ligadas a infraestruturas rodoviárias buscando, em primeiro lugar, apontar a relações entre morfologia, estrutura e paisagem. Em seguida, a partir de obras e autores modernos, articula parâmetros teórico-conceituais a seus desdobramentos físico-espaciais, buscando interpretações sobre a forma urbana, não enquanto soma de objetos construídos, mas como conjunto de relações que estruturam o espaço. Esta estruturação pode, certamente, acarretar em problemas e limitações, mas a perspectiva aqui é a de um entendimento que abra possibilidades para uma melhor atuação futura, em diálogo com condições comuns a este tipo de infraestrutura e com as especificidades de cada território. 


\section{SÃOPAULO15 - $17 \cdot$ LISBOA $25 \sim 26$ JUN 2020}

\section{Hierarquia vs. solidarização}

Do ponto de vista da forma urbana, as grandes rodovias são eixos que canalizam o fluxo e ampliam as velocidades dos veículos, possibilitando o vencimento de grandes distâncias em tempos curtos, através do que Secchi (2016, p. 41) chamou de tubos. São infraestruturas que, por meio de operações de especialização e de setorização, estabelecem novas relações e hierarquias com seu território, separando-se programaticamente de seu entorno, acessado por meio de grandes trevos, alças ou agulhas viárias.

A racionalidade que serve de base à construção destes tubos atende à demanda crescente por mobilidade, através da construção de maiores infraestruturas e a definição de poucos e claros pontos de acesso ao sistema, que absorvem mais tráfego, a mais altas velocidades e às custas de menor conectividade (PELLEGRINI, 2016, p. 50-54). A separação e o isolamento provocados por infraestruturas altamente especializadas e hierarquizadas tendem a constituir barreiras e a promover a construção de enclaves que negam qualquer caráter poroso ou permeável ao território.

Um sistema ou desenho urbano antagônico ao rodoviário e, portanto, não seletivo, não hierarquizado, mais permeável e solidário, pode ser buscado no que Secchi (2016, p. 40), define sobre o conceito de esponja, segundo o qual uma malha mais diversa e densa de estradas menores é um substrato que estabelece maior contato com a "cidade difusa", suas habitações, campos, comércio e atividades produtivas ${ }^{1}$. A esponja é um tipo de superfície resiliente e adaptativo, integrado ao território, capaz de se autorregular e modificar com o tempo e de sugerir os conceitos de porosidade, acessibilidade e permeabilidade, como maneiras de absorver as demandas de uma sociedade múltipla, complexa e diferenciada.

Fabiana Izaga (2009, p. 77-78) utiliza o conceito de aderência para referir-se ao grau de registro que uma rede exerce sobre o território no qual se implanta. A característica de baixa aderência corresponderia a infraestruturas autônomas e ligadas unicamente às suas próprias regras de circulação, enquanto que a alta aderência se associaria às qualidades de capilaridade ou solidarização entre infraestrutura e território e, portanto, ao potencial de tornar-se mais flexível, acessível e receptivo a atividades e meios variados de deslocamento.

A malha urbana, ou o sistema do gridiron, enquanto esquema de estruturação urbana é, nas palavras de Albert Pope (2014 , p. 19), um elemento de simplificação e ao mesmo tempo de distinção; prescritivo, porém ambíguo, oferecendo enorme interconectividade e flexibilidade, se lido, para além de um ícone redutivista, como um diagrama de diversidade e complexidade, no qual, mais que um desenho particular - retilíneo ou orgânico - importa uma lógica, uma organização interna (p. 11-12).

Esta lógica se encontra, por exemplo, no plano de extensão para Barcelona, de Ildefons Cerdà (1859), no qual, sobrepondo ao território externo à cidade medieval uma malha de $113 \times 113$ metros, determinou-se uma organização de quadras que permitiria a distribuição igualitária de serviços, vias e infraestrutura, ao longo da expansão urbana. Neste sistema, a compreensão sobre o que seria a morfologia urbana não estaria ligada à concepção da forma arquitetônica, na figura de grandes edifícios, monumentos e avenidas, mas associada a um diagrama que promoveria a distribuição proporcional de capitais, recursos, população e políticas públicas, integrados por um sistema homogêneo de circulação.

\footnotetext{
${ }^{1}$ Em pesquisas sobre a planície do Veneto, na Itália, Bernardo Secchi e Paola Viganò assumem o caráter difuso e disperso do território, estudando de que maneiras se podem extrair lições para uma urbanização mais adaptativa e resiliente.
} 


\section{SÃO PAULO15 17 LISBOA $25 \sim 26$ JUN 2020

\subsection{Uma questão de escala}

Aos dois tipos de sistemas comentados - um hierárquico, especializado e linear e outro homogêneo, flexível e poroso - podem-se acrescentar duas reflexões que permitem relativizar o condicionamento da forma urbana pela infraestrutura, representadas em raciocínios diagramáticos. A primeira parte do que levanta Aureli (2018), sobre um processo de renovação urbana na Philadelphia, nos anos de 1950. Organizada com base em uma extensa malha ortogonal, a cidade vinha passando por um processo de crescimento suburbano, no pós-guerra, o qual tentava-se reverter com investimentos sobre o centro, que terminariam por atrair o capital financeiro e expulsar populações mais vulneráveis economicamente.

Neste contexto, Louis Kahn, observando a organização reticular da área central e convencido de que o principal problema para o tráfego, constantemente congestionado, eram os repetidos cruzamentos e pontos de redução ou parada a cada esquina, projeta um novo esquema de circulação para suas ruas, hierarquizando suas velocidades desde a categoria de vias expressas até vias peatonais, de maneira a reduzir consideravelmente o número de cruzamentos. Kahn projeta, ademais, estrategicamente ao redor da área de intervenção, grandes torres cilíndricas que funcionariam como estacionamentos, incentivando o uso do carro particular e estruturando a cidade a partir da organização de fluxos. Dentro do perímetro delimitado pelos cilindros - ou baías, em oposição aos rios, que seriam as vias expressas (AURELI, 2018, p. 163) -, a circulação se daria somente a pé.

Uma segunda reflexão parte de Secchi (2016, p. 35), ao comentar a oposição entre hierarquia e isotropia, quando contrapostas a diferentes escalas urbanas. O autor afirma que, em uma rede isotrópica, não há direções prevalentes; cada ponto é conectado igualmente a todos os outros, em uma conformação oposta à de hierarquia, que se aproxima, portanto, das qualidades de porosidade e aderência, relativas ao sistema do gridiron ou a territórios "esponjosos".

Secchi observa que, entre as duas categorias antagônicas, não há limites definidos ou clara separação, e que diferentes territórios ou organizações espaciais podem ser, ao mesmo tempo, fortemente hierarquizados em uma escala ampliada e consideravelmente isotrópicos em uma escala local, ou vice-versa. Assim, por exemplo, uma ocupação baseada em assentamentos formados por redes de infraestrutura isotrópicas pode estar inserida em um sistema territorial cuja característica geral é nucleada.

Esta relação pode ser encontrada num tipo de organização espacial à qual Pope chamou de ladder, exemplificado pelo projeto de transformação do distrito de Marquette Park, em Chicago, por Ludwig Hilberseimer, que consistiu na transformação de malhas abertas e contínuas em seguidas unidades fechadas, com vias em cul-de-sac, a partir da eliminação de ruas essenciais e de boa parte dos cruzamentos (Figuras 1 e 2) $)^{2}$. Essa operação transformou um grid, antes contínuo, em uma série de figuras bloqueadas e isoladas, conectadas entre si apenas por eixos arteriais. Demolição após demolição, apagamento após apagamento, a área de espaço vazio supera a área de forma construída e emerge a figura do ladder, como sistema hierarquizado, distribuído a partir do que Christopher Alexander (1965) chamou de configuração "em árvore", composto por pequenos trechos de grids isolados.

\footnotetext{
${ }^{2}$ A palavra ladder representa o que, em Português, se conhece por "escada de marinheiro", e se assemelha, em termos de organização urbana, a um esquema em "espinha de peixe".
} 


\section{SÃOPAULO15 17 LISBOA $25 \sim 26$ JUN 2020

No mecanismo descrito, o apagamento da malha cessa a continuidade do que antes, de maneira simplificada, porém clara, se constituía como um arranjo entre espaço e forma. A configuração resultante é formada por um eixo linear, a partir do qual se destacam afluentes ou "degraus", fechados sobre si mesmos, que podem ser, eventualmente, resquícios de um tecido outrora contínuo que resulta obstruído, descontinuado.
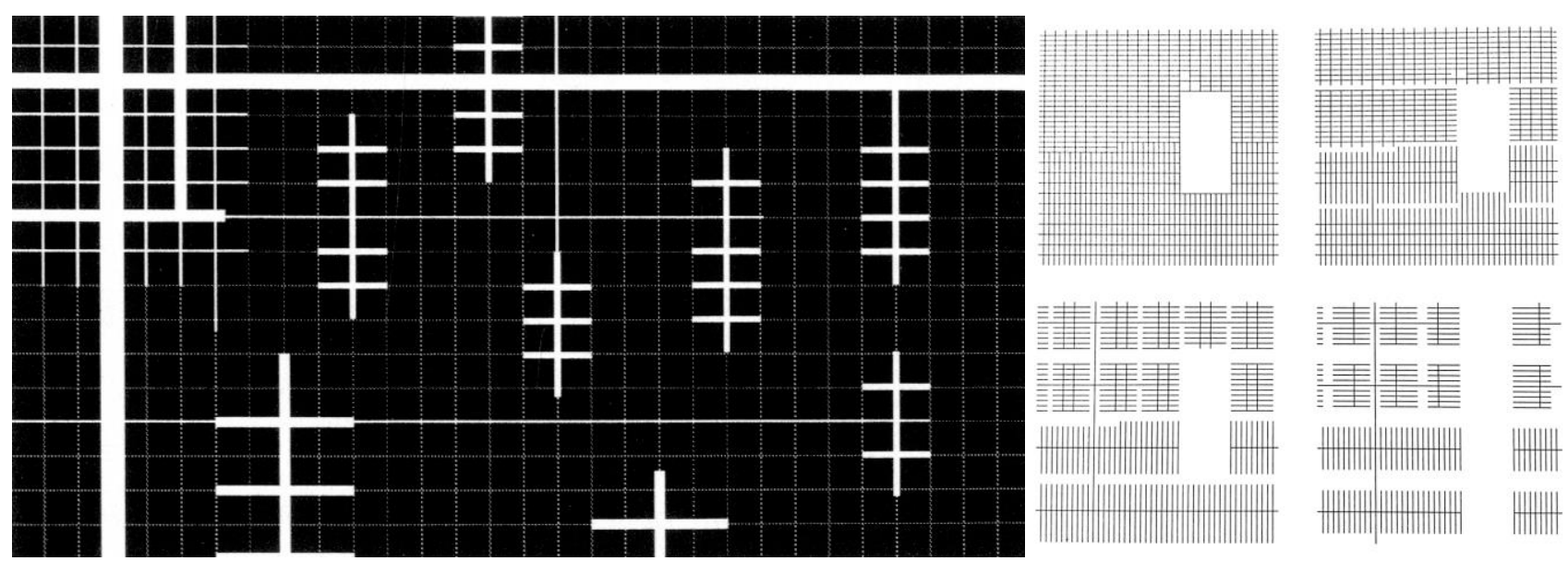

Figuras 1 e 2 - The Super Urban Stage. Diagramas do Ladders e Erosão do Grid, no replanejamento do Marquette Park, em Chicago, por Hilberseimer. Fonte: POPE, 2014

O próprio Pope $(2014$, p. 156) alerta para a diferença entre uma escala global e uma escala local de organização, na metrópole do pós-guerra, cuja forma geral se percebe frágil e desorganizada, marcada por amplos vazios e espraiamento urbano. A mesma metrópole, no entanto, se observada a partir da ordem interna aos assentamentos que pontuam os grandes vazios, nota-se organizada e delimitada, composta por figuras de formas mais controladas e coesas.

\section{Forma x espaço: padrões de expansão}

Infraestruturas rodoviárias, além de aumentarem a eficiência do tráfego motorizado e otimizarem os deslocamentos entre localizações distantes, tiveram como mote e diretriz a expansão da ocupação urbana, conduzida para além de regiões centrais, nas metrópoles onde se implantaram. Não à toa, a noção de tábula rasa, como uma folha em branco, sobre a qual se esboçam ideias e desenhos, foi buscada como situação ideal para que se explorassem ao máximo os potenciais sugeridos por um universo cultural do qual surgiram inúmeras concepções de cidade.

Embora se possa buscar na expansão urbana, guiada por eixos infraestruturais lineares, princípios comuns a diversos projetos e teorias, não se pode afirmar que as grandes rodovias metropolitanas sigam estritamente um modelo ou proposta específica. É, no entanto, interessante buscar pontos comuns entre trabalhos que levaram ao extremo a especulação sobre novas cidades, em um momento histórico no qual novas possibilidades eram obstinadamente exploradas. Guardadas suas especificidades, diferentes protagonistas do urbanismo moderno propuseram, cada um à sua maneira, modelos de cidade que tiveram como marca a 


\section{XII $\quad$ SÃO PAULO $15 \sim 17 \cdot$ LISBOA $25 \sim 26$ JUN 2020}

abertura do tecido urbano tradicional e a infusão de concepções altamente idealizadas de espaço (POPE, 2014 , p. 242).

\subsection{Modelos Lineares}

Apesar de efetivamente reconhecível em diversos modelos urbanos, na busca constante de expansão e na possibilidade da tábula rasa como laboratório aberto a experimentações, uma espécie de inversão entre espaço e forma construída reside na organização redutiva do que Pope denominou ladder. $O$ que Daniel Köhler (2016, p. 175) chama de "dissolução do lote" é a subtração de segmentos de uma malha preexistente, que permanece residualmente, como uma série de cul-de-sacs. Estes são, por sua vez, os pontos terminais das Settlement Units de Ludwig Hilberseimer, algo como "unidades de assentamento ou ocupação", cuja característica principal é uma organização espacial orientada sempre a partir de um eixo principal, do qual partem "espinhas" transversais, como partes elementares de um esquema urbano configurado com base em uma linha contínua e adaptável.

O princípio definido por Hilberseimer tem como precursora a Cidade Linear, de Arturo Soria y Mata, publicada pela primeira vez em 1882, como variação ou complemento à Cidade Jardim, de Ebenezer Howard, cuja estruturação derivaria essencialmente da necessidade de circulação. No esquema de Hilberseimer, no entanto, a unidade de ocupação básica teria papel preponderante, a partir da qual a infraestrutura poderia se adaptar. Assim, o posicionamento dos edifícios em relação à insolação e aos ventos dominantes determinaria a configuração geral dos assentamentos. Da mesma maneira, o dimensionamento das zonas comerciais, industriais, educativas, comunitárias, agrícolas e de lazer correspondentes ditaria o número de habitantes e a área total de total de cada unidade, cujas distâncias ao eixo principal deveriam basear-se em dimensões caminháveis (KÖHLER, 2016; POPE, 2014).

A disposição destes espaços obedeceria a uma série de regras ou parâmetros que não deveriam, no entanto, responder a formas predefinidas, possibilitando a repetição esquemática e adaptativa de um elemento básico, ao longo de um eixo contínuo, porém não necessariamente retilíneo. Dessa maneira, a nova cidade de Hilberseimer ofereceria flexibilidade, adptabilidade à topografia, estrutura viária moderna, legível e grandes espaços abertos (POPE, 2014 , p. 73), a partir do que Köhler chamaria de um princípio de combinação mereológica ${ }^{3}$.

Um outro projeto de cidade cuja estrutura básica partiria de um eixo principal articulado a uma sequência de transversais seria a Rush City Reformed, desenvolvida por Richard Neutra, em meados dos anos 20 (Figura 3). De caráter fortemente especulativo, propunha-se como uma cidade regional construída a partir do zero, pensada para uma região metropolitana nos EUA, com população de um milhão de habitantes.

Sua configuração espacial trazia, ao longo do eixo principal, grupos de edifícios comerciais e administrativos, com ferrovia subterrânea e uma autoestrada rebaixada em relação ao nível de circulação peatonal, que se faria em um patamar superior e eliminaria a necessidade de travessias em nível. As vias perpendiculares seriam acessadas por trevos, dando alcance a áreas verdes, parques, zonas residenciais, industriais e

\footnotetext{
${ }^{3}$ Mereologia é a teoria das relações de parte para o todo e de parte para parte, dentro de um todo.
} 


\section{SÃO PAULO15 17 LISBOA $25 \sim 26$ JUN 2020 \\ Seminário Internacional de \\ Seminario Internacional de Investigação em Urbanismo Investigación en Urbanismo}

equipamentos comunitários (COLLINS e FLORES, 1968, p. 68-69). É interessante notar como o trabalho de Neutra apresenta similaridades com a Vertical City, que Hilberseimer desenvolveu ao longo dos anos 1920, na Alemanha - e, portanto, antes das Settlement Units, dos anos 40, quando passou a viver nos EUA.

Ambos projetos separam verticalmente as categorias de circulação, distribuindo diferentes modais de forma homogênea, a partir de sistemas reticulados de larga escala superpostos, além de se utilizarem de tipologias básicas de edificações, que aludem a uma arquitetura genérica e em nada formalista, baseada nos princípios da repetição e da industrialização (AURELI, 2011, p. 13-14).

A Rush City, de Neutra, foi pioneira na importância dada à acessibilidade urbana, que deveria surgir de um tratamento integrado dos diferentes modos de transporte. Trens suburbanos, trens de alta velocidade, transporte automobilístico e inclusive transporte aéreo deveriam distibuir-se e comunicar-se por grandes nós que, como estações intermodais, unificariam e interligariam os diferentes sistemas (RIBEIRO, 2007, p. 7374).
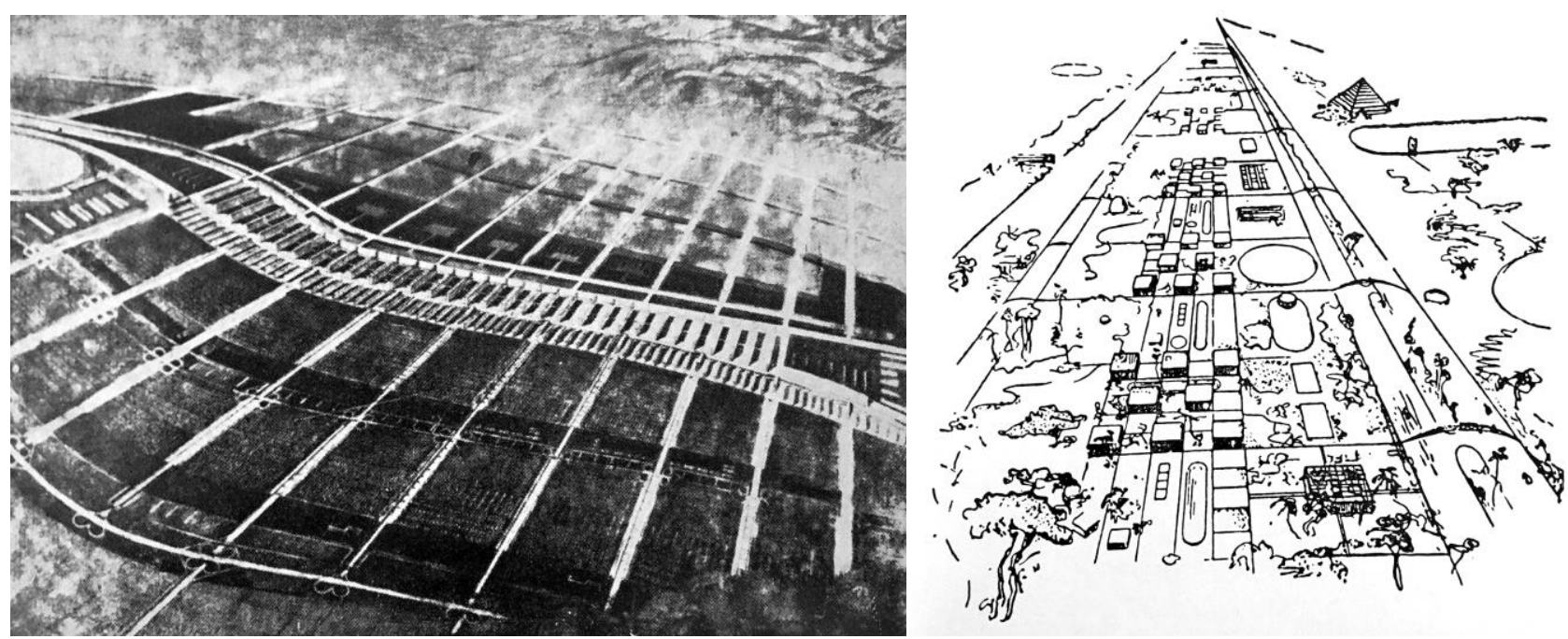

Figuras 3 e 4 - The Rush City Reformed, de Richard Neutra e Magnitogorsk, de Leonidov. Fonte: COLLINS e FLORES, 1968

Em 1930, o arquiteto russo Ivan Leonidov, junto ao grupo OSA, apresentou para a cidade industrial de Magnitogorsk, uma proposta híbrida, entre cidade linear e cidade reticulada (Figura 4). Projetada de fato como uma espécie de malha contida entre dois eixos longitudinais, esta cidade deveria-se implantar em uma área rural e inabitada da Rússia socialista, refletindo, de acordo com princípios suprematistas/construtivistas, uma série de lógicas que possibilitariam a dispersão e a descentralização urbanas, afastando-se da densidade e das características burguesas da metrópole liberal (COLLINS e FLORES, 1968, p. 72; FEFERMAN, 2007, p. 241).

Ao longo de $36 \mathrm{~km}$, Magnitogorsk se organizaria entre duas faixas paralelas de transportes, com residências e estruturas de pequenas escalas na porção intermediária, equipamentos públicos e de lazer de um lado, parques e escolas do outro, externamente aos eixos principais. A infraestrutura reticulada conjugaria 


\section{SÃOPAULO15 $17 \cdot$ LISBOA $25 \sim 26$ JUN 2020}

densidade e dispersão, paisagem e urbanização, em um sistema aberto, de crescimento infinito, porém contido em uma espécie de raia.

Diferentemente de Leonidov, o também russo, teórico N. A. Miliutin projetou, para uma cidade que abrigaria uma fábrica de tratores, o que seria um tipo de cidade linear dividida em faixas paralelas. Concebida como uma "metáfora da linha de produção", esta cidade seria análoga a uma "planta industrial gigante" (COLLINS e FLORES, 1968, p. 63), com seis faixas lineares, sem eixos transversais ou variações sequenciais, classificadas por suas funções: ferrovia, zona industrial, um cinturão verde separando-a da área residencial seguinte, uma rodovia e a área de parques, adjacente ao Rio Volga (POPE, 2014 , p. 66).

O modelo de Miliutin foi aproveitado por Le Corbusier em sua criação para Os Três Estabelecimentos Humanos, em que "centros radioconcêntricos de trocas", de comércio, "do pensamento", da administração e do governo, se conectariam por "cidades lineares industriais", "ditadas fundamentalmente pela geografia" (LE CORBUSIER, 1979, p. 85/121). O conjunto, em cujo centro haveria "unidades de exploração agrícolas" teria, ainda, eixos de mobilidade hidroviária, rodoviária e ferroviária, formando composições triangulares de escala regional. (BOYER, 1989, p. 89).

A ideia de triangulação é o sétimo dos dez "princípios fundamentais" da Cidade Linear de Arturo Soria y Mata, para quem "a arquitetura racional das cidades" deveria adaptar-se "ao meio-ambiente criado pela geografia e pela história" (TERÁN, 1964, p. 15), em uma cidade de tipo ideal, orientada à circulação e à descentralização, de proporções ilimitadas. Apresentada muito mais como esquema, processo ou sistema, sem a pretensão de se consolidar enquanto forma arquitetônica resolvida, a Cidade Linear se posicionou no debate urbanístico sob a conotação de uma proposta aberta e experimental, radicalmente contraposta, por seus princípios básicos, à cidade nuclear, concêntrica (COLLINS e FLORES, 1968, p. 21; FEFERMAN, 2007, p. 49).

Nesta cidade-sistema, sem limites ao crescimento, todas as classes sociais teriam lugar, diferentemente do que acontecia na cidade centralizada, saturada, que sofria com a especulação imobiliária e a distribuição desigual da propriedade. Uma "colonização interior" atuaria contra a emigração de uma população rural e pobre para a cidade, em busca de renda e sustento. Ademais, buscava-se combinar o trabalho agrícola com a descentralização da indústria, além de equilibrar a oposição, então vigente, entre a cidade e o campo, levando-se, junto aos meios de transporte, melhores condições de habitação a regiões periféricas (RUBIO, 2017, p. 76).

No entanto, o próprio reconhecimento da existência de uma cidade central à qual se opunha uma outra, periférica, somado à baixa densidade e reduzido volume edificado das cidades lineares foram motivos de críticas ao modelo de Soria y Mata, por sua dependência a uma área mais consolidada, pouca autonomia e por um padrão de ocupação que se opunha à própria dinâmica do fato urbano, tornando-a não mais que uma "grande via povoada" (TERÁN, 1964, p. 17) ou, nas palavras de Peter Hall (2009, p. 131), um "subúrbiodormitório urbanizado segundo as leis da especulação comercial".

\subsection{Modelos nucleados}

O modelo da Cidade Jardim, apesar de ter, durante muito tempo, funcionado de maneira complementar ao linear, pode ser contraposto a ele, em pelo menos dois aspectos. Um tem a ver com sua própria dinâmica, enquanto sistema teórico, mais fechado, direto e autônomo e mais direcionado ao pragmatismo da execução 


\section{SÃO PAULO15 17 LISBOA $25 \sim 26$ JUN 2020

do que a um processo intelectual de debates e aperfeiçoamento. O segundo aspecto tem relação com o caráter nuclear e mais isolado, claramente antagônico à continuidade da Cidade Linear. O padrão de assentamento e de mobilidade da Cidade Jardim se liga diretamente ao transporte ferroviário e a um tipo de expansão urbana polinuclear, reproduzida em diversas partes do mundo, especialmente a partir do fim da segunda guerra mundial.

Ebenezer Howard, pai da ideia da Cidade Jardim, via, na metrópole industrial, problemas ligados ao excesso de concentração, insalubridade, condições indignas de moradia, trabalho e movimentação da população. No entanto, não desconsiderava as virtudes sociais da grande cidade, reunidas em Londres como sua principal referência. Para ele, cooperação, relações humanas, ciência, arte, cultura e religião deveriam ser valorizadas e combinadas às grandes qualidades do campo, em uma espécie de terceira via que conjugasse ambas em comunidades cooperativas descentralizadas, autogovernadas e autônomas (HALL e WARD, 1998).

Estas ocupações proveriam habitação, serviços, indústria e emprego, replicando-se, ao atingirem seus limites, em outros assentamentos similares. O conglomerado de pequenas cidades separadas por cinturões verdes seria a concretização da configuração polinuclear, conjugando as virtudes da cidade às do campo. A Social City não negaria a existência de um centro metropolitano mais antigo e, por vezes, superpopuloso, mas controlaria sua expansão, promovendo a descentralização, a partir do estabelecimento de núcleos descontínuos e autônomos (HALL, 2009, p. 109; POPE, 2014 , p. 78).

Esta configuração, no entanto, teve desdobramentos imprevistos pelo projeto das Garden Cities, instigados por atores interessados na ampliação do modelo, na possibilidade de lucro e na criação de bairros que diferenciassem classes burguesas e proletárias. Assim formaram-se subúrbios-jardim, servidos por transporte ferroviário, porém sem indústrias. Estes assentamentos foram determinantes para a expansão urbana reproduzida a partir da metade do século XX, especialmente na Europa e nos EUA. Seu padrão, no entanto, para que seja esclarecido, pede uma reflexão anterior, sobre a cidade moderna e os primeiros subúrbios ferroviários.

\subsection{A malha como sistema}

Albert Pope (2014 , p. 22) busca as palavras de Rosalind Krauss (1979), ao referir-se ao sistema do gridiron enquanto suporte a um campo espacial infinito, que se estende em todas as direções (Figura 5). Esta leitura, definida como centrífuga, permite compreender a malha urbana, enquanto princípio de expansão e lógica de organização, como um esquema não excludente, ao qual qualquer ponto ou extensão pode ser absorvido, sem que se precisem estabelecer limites definidos. Nas palavras de Pope (2014 , p. 23) as coordenadas da malha, para as quais não se pode determinar um exterior são, basicamente, todo e qualquer lugar.

Com base neste esquema, uma cidade poderia expandir-se de maneira contínua, ininterrupta. $\mathrm{O}$ transporte ferroviário possibilitou povoamentos nucleares suburbanos que, embora se afastassem de regiões centrais, se expandiam sob os mesmos princípios. Foi assim no Rio de Janeiro do século XIX que, a partir da construção da Estrada de Ferro Dom Pedro II - atual Estrada de Ferro Central do Brasil - se expandiu rumo a norte e noroeste da ocupação inicial da cidade, com a instalação de estações ferroviárias que originaram pequenos núcleos urbanos. Nestes locais, grandes glebas agrícolas foram sendo loteadas, outros sistemas de transporte, mais leves, foram adicionados e a expansão urbana tomou grandes proporções. 


\section{SÃOPAULO15 17 LISBOA $25 \sim 26$ JUN 2020

Processo similar, porém, em escala muito maior, aconteceu, também com início na segunda metade do século XIX, na região de Los Angeles e do Vale de São Fernando, na Califórnia. Reyner Banham (2013, p. 58-60) explica que as cinco linhas ferroviárias - posteriormente substituídas por rodovias expressas - que partiam do pueblo, ocupação originária central da cidade, rumo a norte, sul, leste e oeste, delinearam a forma de sua expansão, prefigurando um padrão de movimento que a caracterizaria daí em diante.

O loteamento de terras ligadas às estações ferroviárias avançou de forma rápida, intensificada pela chegada de grande número de imigrantes, que se distribuíram, rumo a variadas direções, estabelecendo núcleos urbanos com vida econômica e institucional independente da ocupação central. Guiada por interesses imobiliários, a ocupação da região se deu pelo lançamento de uma imensa infraestrutura em malha, que Pope (2014 , p. 162) diferencia da que foi empregada em Orange County, imediatamente ao sul de Los Angeles. Aí, uma organização descontínua, fechada e caracterizada por condomínios vigilados, shopping centers exclusivos e enclaves de negócios, se associa à figura do ladder, ou de uma ocupação típica dos anos do pós-segunda guerra, cuja lógica, oposta à da malha e com base nas reflexões de Rosalind Krauss, o autor classifica como "centrípeta".
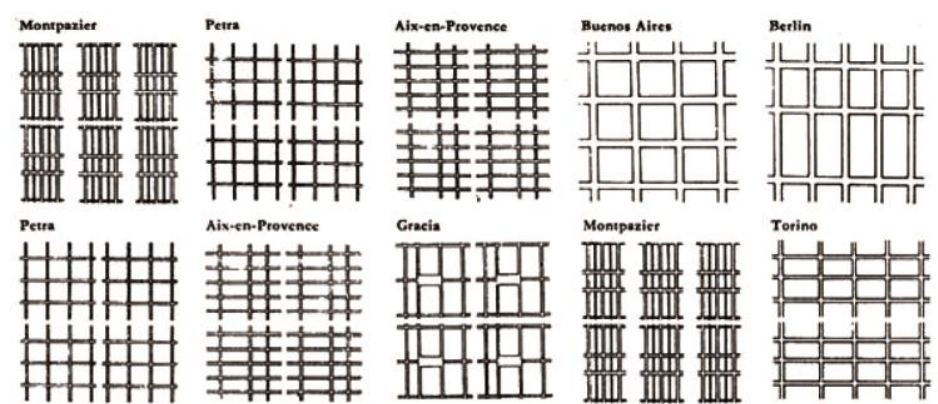

Tracis
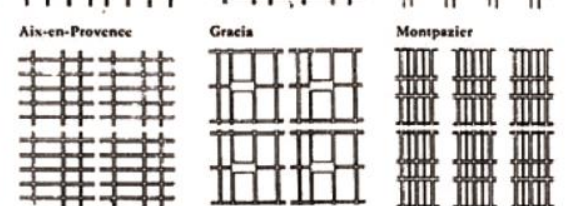

Petra Aix-en-Provence

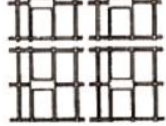

Gracis

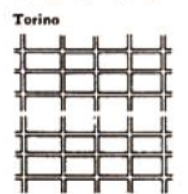

silbaso

Madrid

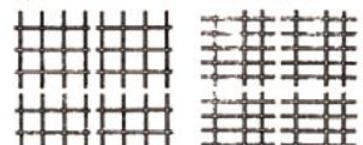

समिम

Atenas

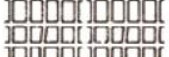

y

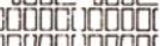

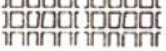
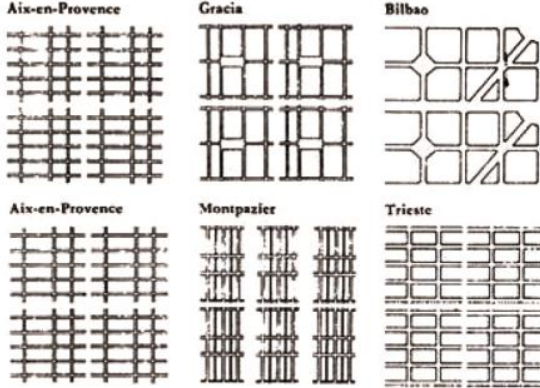

Tricute
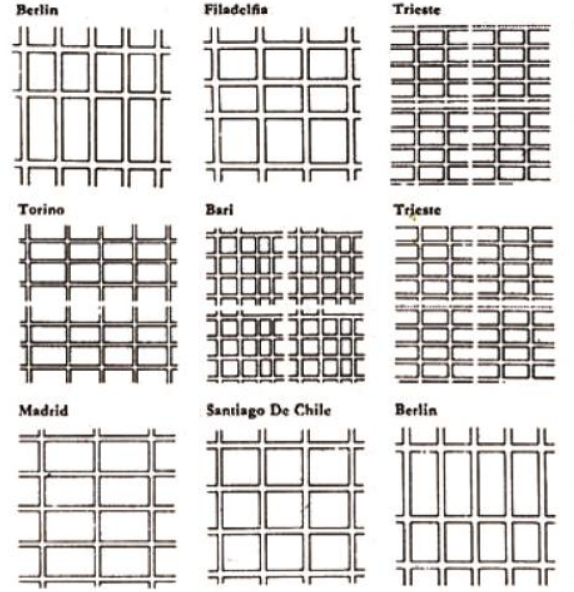

Bari
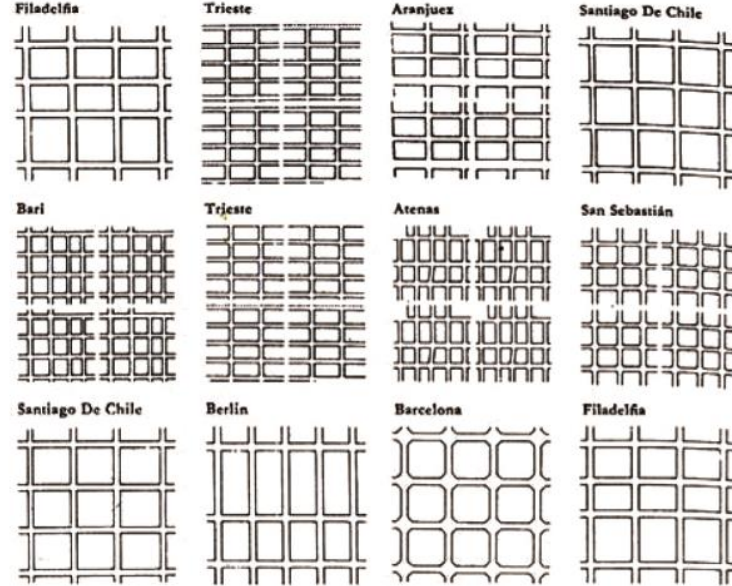

Santiago De Chile

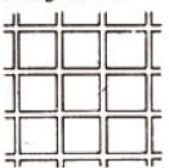

Bari

Figura 5 - Retículas urbanas variadas. Fonte: Solà-Morales, 2010, p. 60
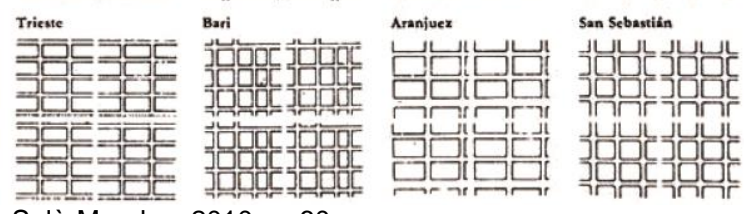

San Sebastian
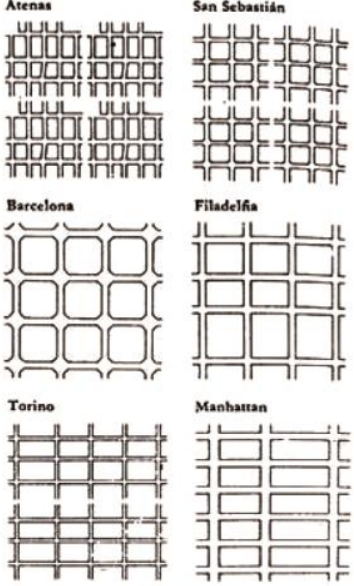

No arranjo espacial centrípeto, marcado por forte diferenciação entre forma urbana e espaço, ou figura e fundo, mais que uma organização interna, reproduz-se um exterior, um lado de fora, cuja condição se associa vigorosamente ao termo "residual" (POPE, 2014 , p. 23). Aos espaços externos à formação protagonista do ladder, o autor denomina elipses, inevitáveis subprodutos do desenvolvimento centrípeto, aquilo que sobra, entre eixos viários e enclaves fechados sobre si próprios, em permanente estado de 


\section{SÃOPAULO15 $17 \cdot$ LISBOA $25 \sim 26$ JUN 2020}

desorganização, por distinção a seu oposto. A esta desorganização Pope associa o conceito de entropia, que no campo da Física condiz com o grau de desordem entre moléculas de um sistema.

Em sentido similar, o geógrafo Milton Santos (2002, p. 174) comenta a ação de vetores entrópicos da modernização hegemônica sobre a organização do espaço urbano, cuja ordem se estabelece em benefício próprio e exclui àqueles não inseridos em seus círculos. Como resultado deste processo, surgem áreas de urbanização precária, marcadas pela informalidade e onde a ocupação costuma se vincular ao acesso a infraestruturas de mobilidade que, bem ou mal, oferecem incremento às condições de acessibilidade da população.

\section{Considerações Finais}

É preciso observar a urbanização alavancada pelas infraestruturas rodoviárias a partir de uma perspectiva crítica, porém aberta. Associá-la à causa do colapso que marca nossas metrópoles e desprezar os parâmetros e relações que promove significa abdicar de seu reconhecimento e, em consequência, da produção de conhecimento para que se enfrentem questões urgentes.

Projetos e teorias do urbanismo moderno podem apontar a vocabulários e entendimentos físico-espaciais dinâmicos, complexos e ambiciosos quanto a relações entre infraestruturas e seus territórios. Muito mais que meros dispositivos de mobilidade ou vetores de expansão urbana, eixos rodoviários podem incorporar camadas, adaptar-se a diferentes condições e proporcionar paisagens variadas, porém externas a concepções tradicionais de cidade.

Forma e movimento, linearidade e transversalidade, especialização e flexibilização, desempenho e aderência, grandes e pequenas escalas podem representar, a partir de leituras compartimentadas, qualidades incompatíveis. No entanto, se observadas, descritas e articuladas em chave de oportunidade, podem potencializar a essência do que é o fato metropolitano em si, integrado e unificado como sistema, porém composto por incontáveis partes e relações distintas.

\section{Referências}

ALEXANDER, C. A City is not a Tree. The Architectural Forum, v. 162, p. 58 - 62, 1965.

ALONZO, É. Du rond-point au giratoire. Marseille: Éditions Parenthèses, 2005.

AURELI, P. V. The Possibility of an Absolute Architecture. Cambridge: MIT Press, 2011.

AURELI, P. V. Habitando la Abstracción: Notas a Ladders, de Albert Pope. In: POPE, A. Ladders. Houston: Architecture at Rice, 2014.

AURELI, P. V. Appropriation, Subdivision, Abstraction: A Political History of the Urban Grid. Log, Nona York, v. 44, p. 139-167, 2018.

BANHAM, R. Los Angeles: a arquitetura de quatro ecologias. Tradução de Marcelo Brandão Cipolla. São Paulo: WMF Martins Fontes, 2013.

BOYER, M. C. Mobility and Modernism in the Postwar City. Modernist Visions and the Contemporary American City, Austin, v. 5, p. 86-104, 1989. 


\section{XII

COLLINS, G. R.; FLORES, C. Arturo Soria y la Ciudad Lineal. Madrid: Revista de Occidente, 1968.

DOMINGUES, Á. A Rua da Estrada. Cidades - Comunidades e Territórios, Porto, p. 59 - 67, Dezembro 2010. ISSN 20/21.

HALL, P. Cidades do Amanhã: uma história intelectual do planejamento e do projeto urbanos no século XX. Tradução de Pérola de Carvalho. São Paulo: Perspectiva, 2009.

HALL, P.; WARD, C. Sociable Cities: the Legacy of Ebenezer Howard. Chichester: John Wiley \& Sons Ltd, 1998.

IZAGA, F. Mobilidade e Centralidade no Rio de Janeiro. Tese de doutorado - PROURB, UFRJ. Rio de Janeiro. 2009.

KLEIMAN, M. De Getúlio a Lacerda: um "rio de obras" transforma a cidade do Rio de Janeiro. As obras públicas de infraestrutura urbana na contrução do "novo Rio" no período 1938-1965. Tese de doutorado - FAU-USP. São Paulo. 1994.

KÖHLER, D. The Mereological City: a reading of the works of Ludwig Hilberseimer. Tradução de Verlag. Innsbruck: Bielefeld, 2016.

LE CORBUSIER. Os Três Estabelecimentos Humanos. Tradução de Dora Maria de Aguiar Whitaker. $2^{2}$. ed. São Paulo: Perspectiva, v. 96, 1979.

PELLEGRINI, P. Pipes and Sponges: The Implicit Project for the Construction of the Central Veneto Area. In: VIGANÒ, P.; FABIAN, L.; SECCHI, B. Water and Asphalt: The Project of Isotropy. Zurique: Park Books, 2016. p. 44-57.

POPE, A. Ladders. Houston: Architecture at Rice, 2014.

RIBEIRO, P. P. A. Teoria e Prática: a obra do arquiteto Richard Neutra. Tese de Doutorado - FAU USP. São Paulo. 2007.

RUBIO, M. Á. M. La "Ciudad Lineal" alternativa al crecimiento imparable de la gran urbe actual. Estoa, Cuenca, v. 6, n. 11, p. 71-80, Julho-Dezembro 2017.

SANTOS, M. A Natureza do Espaço. Técnica e Tempo. Razão e Emoção. São Paulo: EDUSP, 2002.

SECCHI, B. El Espesor de la Calle. In: MARTÍN RAMOS, Á. La Calle Moderna en 30 Autores Contemporáneos y un Pionero. Barcelona: Universitat Politècnica de Catalunya, 2014. p. 203-207.

SECCHI, B. Isotropy versus Hierarchy. In: VIGANÓ, P.; FABIAN, L.; SECCHI, B. Water and Asphalt: TheProject of Isotropy. Zurique: Park Books, 2016. p. 34-43.

SOLÀ-MORALES, M. D. Cerdà / Ensanche. Barcelona: Edicions UPC, 2010.

TERÁN, F. D. Revisión de la Ciudad Lineal. Revista Arquitectura, Madrid, v. 72, p. 3-20, 1964.

VILLAÇA, F. Espaço Intra-Urbano no Brasil. São Paulo: Studio Nobel, 2001. 


\section{SÃOPAULO15 $17 \cdot$ LISBOA $25 \sim 26$ JUN 2020}

Seminario Internacional de Investigação em Urbanismo

WALL, A. Flujo e Intercambio. La Movilidad como Atributo de la Urbanidad. In: MARTín RAMOS, Á. La Calle Moderna en 30 Autores Contemporáneos y un Pionero. Barcelona: Universitat Politècnica de Catalunya, 2014. p. 215-220. 